\title{
Bongani's Story
}

\author{
Bongani Mapumulo
}

\section{REFLECTIONS}

When it comes to my masculinity as a Black South African Zulu man with a physical disability, who is also a student of disability studies, I need to talk about two things. I need to address my culture, how I was raised and how this shaped my non-academic experience of sexuality. But I also need to address how-as a student of social studies-I experience and engage with that literature which I have encountered on the subject of masculinity in the context of physical disability.

I wish I could say there is no fantasy, imagination or expectation which influences sex and sexual relations with ourselves and with others. But again, without these forces, how does sexuality become an enjoyable part of living and loving? The reason I raise the issue of expectations, fantasies and ideals is that, no matter how open-minded, unbiased and objective one tries to be, we all bring these unconscious elements with us when we are getting together with people, especially for the first time.

B. Mapumulo $(\otimes)$

Stellenbosch University, Cape Town, South Africa

(C) The Author(s) 2021

X. Hunt et al. (eds.), Physical Disability and Sexuality, https://doi.org/10.1007/978-3-030-55567-2_7 
Will I live up to the man she sees?

Will I give her everything she needs?

I just hope that when we're done she's pleased.

I hope it's everything you thought it'd be, ob!

Surprisingly, perhaps, these are lyrics by the famous R\&B singer, Trey Songz, who is considered a sex symbol in many ways. You'll notice that there are elements of self-doubt and timidity in these lyrics. My aim in quoting them is to illustrate that if such negative thoughts can affect a famous musician with high status and the supposed ability to attract any woman he wants to, it is only natural that these feelings would be present in all man. In addition, I am deliberately making a musical reference because, in my younger and more impressionable years, music and movies provided a window into the intricacies of love and relationships. If I am going to be completely honest, I should add that, while life has left me with a more pragmatic outlook on love and sex, it would be a lie if I said all those images of perfect romance and fantasy which I encountered in the media I enjoyed, have completely disappeared from my mind.

\section{Us Vs Them: A Small Piece of My Personal Story}

Our upbringing has an enormous effect on the way we turn out as adults. Due to the injury that led to my paralysis at four years old, my parents made a decision to admit me into a so-called 'special school' for children with disabilities. Now, we can probably all agree that's rather an early age to be away from the comforts and amenities of one's home, especially when it happens in the context of a newly acquired paraplegic status. Don't get me wrong-I was extremely lucky to be in a school where I could access the best possible rehabilitation, given the traumatic event I had been through, losing the use of my lower limbs. But, in order to get this help, I now had to be away from home, staying with a bunch of strangers. The rehabilitation process was aided by having access to occupational therapists and physiotherapists, psychologists, teachers and caregivers that seemed to fully understand my needs for accomodation. In addition, the layout of the school was completely accessible. It was a very supportive environment.

And it was an environment marked by many of the normal naughtinesses of school years: just like any kid, my peers and I at the school also got up to no good. My friends and I once got into trouble for being found in a girls' hostel. There was no such thing as visiting hours; the 
school was designed for boys to live in their own space and girls to live in their own, so basically we had broken the rules. If truth be told, I was asking a girl out, but her friends decided to rat on me. Can you believe it? We were punished, and were told that we could not see each other. She had just read Romeo and Juliet or seen one of those "young person being rebellious against the world" type of movies, so we continued to see each other despite the housemothers saying we should separate. How's that for young love?

In our school, we participated in everything that mainstream schools did, like sports and music, and we also took excursions so that we could get to experience the "outside" world every now and again. That's where I think some of my insecurities first arose. By that I mean to say, it was clear to see that when I was out in the world in groups along with schoolmates, the way people would stare at us would make it absolutely clear that they had never seen such a large group of children with disabilities. I never really understood this, because from the point of view of me as a child who had been exposed to disability and kids with disabilities from a very early age, I assumed that an adult would have at some point been exposed to that as well. I think that is what led to a deeply rooted sense of inferiority that developed amongst most of us when it came to mainstream society and feeling left out. We were like fish out of water when we were not within the confines or gates of our school.

Our experience of the outside world came primarily through those school excursions, our time away on holidays, TV, and music. I think every school has that cool group that always seem to know everything that the larger group of kids don't know much about. I remember in our group of friends there was one boy who always had the coolest clothes, had more non-disabled friends that he hung out with during holidays, knew all the movies before most of us saw them, and, of course, had more experience with girls. I remember clearly this one time when we came back from holidays and this friend of ours, I don't want to say his real name, but let's call him Cyril, told us this story of the best New Year's Eve he had, where he went to this party, and he kissed this girl and apparently found his way a bit further south in terms of her anatomical region. He told this story in a very colourful manner and was so proud of himself. Between you and me, I think he added not just extra salt to that story but a few spices from very far away. But hey, we were just a bunch of teenagers who didn't know any better, so we just accepted that story. Now, the point of this story, is that Cyril had apparently hooked up with a non-disabled 
girl while the rest of us were still caught up dating within the scope of girls we found ourselves with at the school. To us, though it is hard to admit it, we saw non-disabled girls to be more of a prize than the girls with disabilities.

That is where my internalised prejudice regarding disability emerged. It was largely based on the issue of us, the children with disabilities, versus the kids of the bigger world that were without disabilities. To have any relationship with a non-disabled person was seen as an achievement, because we saw that as breaking the mould and out of the norm of your equal, your equal being another person with a disability, just like you. We viewed non-disabled people as superior to us, even on a friendly level, and being in a relationship with them was a bigger feat to achieve. I clearly remember that if a girl with a disability was dating a non-disabled boy from the outside world, she was immediately seen as being out of our league, despite her having a disability just like us. We knew just from that, that we stood no chance as boys with disabilities. Besides, which wheelchair user would stand a chance anyway, right?, I used to think. I will come back to discuss how such a view of the outside world informed my identity, disposition and attitude towards women when I eventually left school and integrated into mainstream society. However, it was with all of these experiences in mind, and my recollections of time at a 'special school' at the fore, that I took the following photo. In the picture below, is an area of my new university home, which is accessible to me. However, not all spaces in the world outside of a "special school" are accessible (Image 7.1). These physical spaces are a metaphor for my feelings regarding dating and relationships in the 'terrain' of a segregated school, and in the outside world, respectively: the outside world being fraught with inaccessibility.

There is another aspect that added to my feeling of being inferior as a man with a physical disability. Reflecting upon my own upbringing amongst men in my surroundings, gender roles are quite definitive of a place a person has in society. The culture I belong to is Zulu (I know there is no one definitive experience of a culture, but for the purposes of an understanding of my life, I will represent my experience of being Zulu). My family comes from an area called Umbumbulu, a rural area situated in the south of Durban in the KwaZulu Natal province of South Africa. In Zulu culture (as I experienced it), it is almost as if by virtue of being male, one is already perceived to have leadership qualities, and headship is something of a birthright. With such a birthright, one is expected to 


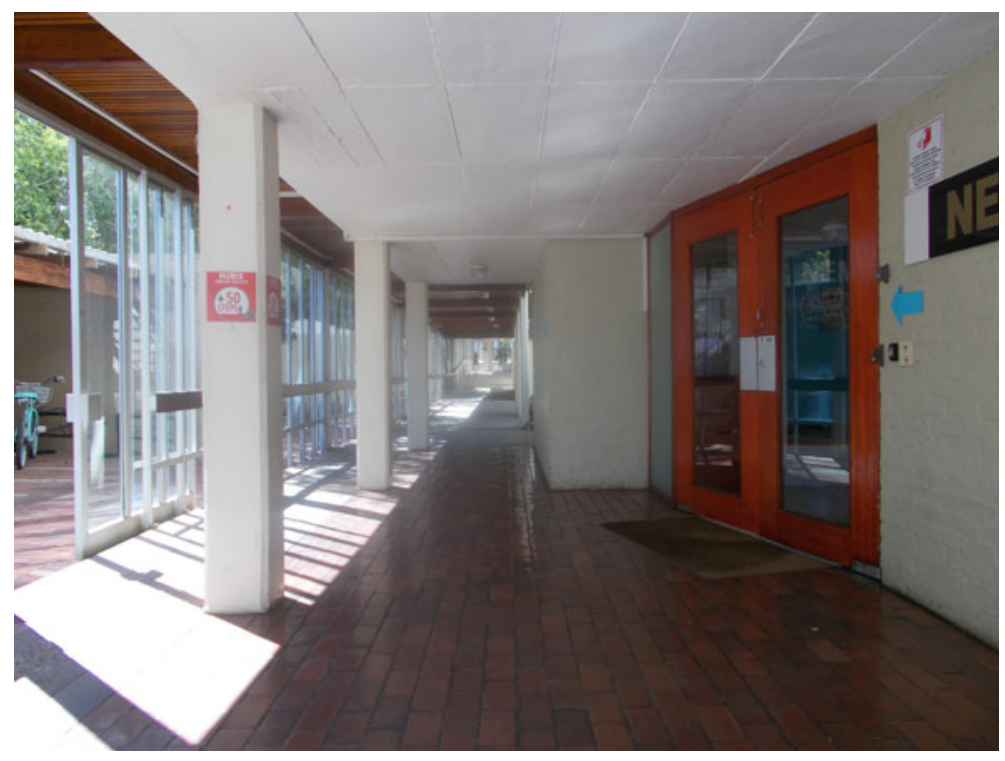

Image 7.1 This is an area in a university residence which is flat and accessible. The image represents a symbol of accessibility aside from what I was exposed to back in my special school. Spaces communicate, they are able to tell you who is welcome and who is not (Photo by Bongani Mapumulo)

embrace and accept the responsibility of being a man and therefore a leader irrespective of whether on has physical prowess. Physical prowess, however, is something that $\mathrm{I}$, as a man with a disability, often battled.

So, broadly, that is my position as I write this piece, personally, as it were. My upbringing and my culture both influenced how I came to experience having a disability, and how I saw this experience in relation to what I witnessed among non-disabled people and what I saw in broaer society. However, beyond my personal reflections on my experiences of physical disability, I am also coming into a phase of my life-as a student of social studies and disability scholarship_-where I am beginning to engage with academic ideas and research about "disabled masculinity". 


\section{How I Think About Masculinity IN THE CONTEXT OF Disability}

Men's bodies have always had to submit to characteristics such as "strength, potency and physical activity" (Connell, 1995, p. 44). Morris (1991, p. 93) goes even further by asserting that:

A social definition of masculinity is inextricably bound with a celebration of strength, of perfect bodies and to be masculine is not to be vulnerable. It is also linked to a celebration of youth and of taking bodily functions for granted.

Disability is often seen to be antithetical to this, a perception fuelled and strengthened by the portrayal of disability in movies as involving weakness, dependency and frailty. A typical portrayal is of a man who loses his masculinity due to some form of impairment. Such frailty can be in the form of impotency and the struggle to adjust to it. A movie most people would have watched is Avatar, where there is a lot of military activity. In this movie, disability is portrayed as incompatible with masculinity through the character Jake Sully, who is not only the physical but also the psychological inferior of his twin brother, who is a man without disability. And of course, in Me Before You, the character of Will Traynor, paralysed from the neck down, would rather die than face the reality of not being able to satisfy a woman sexually due to his disability. The movies' plots are a bit more complicated than that, to be fair, but the dominant narrative in the abovementioned movies is that disability and the main features of masculinity cannot coexist.

While I cannot personally relate to the way men who acquire a physical disability in their adult years struggle to adjust to their male sexuality, Murphy (1987) describes the issue of sexual dysfunction in men akin to being emasculated and effectively castrated. He says that the emphasis many people place on erectile failure is linked to the incorrect view that all sex is by definition penetrative, when in reality sexual and emotional relationships offer a much wider range of expression. According to Tiefer (1995), such an issue further strengthens the idea that normative sex, for men, is and has always been closely linked to the patriarchal and heterosexual ideology rather than to broader and less restrictive ideas about sex and sexuality. Sexual pleasure does not emanate solely from penetration and there are opportunities to look into more diverse experimentations 
and alternative techniques to encounter and experience pleasure and intimacy.

For me personally, learning about how much broader sex can be than just penetration, is important. For most of my life I, like many other people, was also fixated upon the idea of reaching sexual satisfaction by means of penetration and no other way. I attribute this to the information and influence I was exposed to from my earlier ages. This narrow view of sex led me to a state of utter confusion and internal conflict. To make matters worse, I thought of any possible non-disabled sexual partner as by definition superior to me. My role with such a partner would, I thought, have to be submissive (and hence in conflict with what I had learned about what it means to be a man). I had, in short, a view of myself as an outsider in the broader scope of sexual participation: someone who was meant to be dominant but would always - by virtue of social statushave to be submissive. I felt like an "Other", an other in the sense that people with disabilities are excluded from the male identity which relies on superiority and negation from vulnerability. An example of this othering process from a different area of society would be the way White heterosexual men view themselves in opposition to women, Black people and gay men. The way I came to understand society and these different identities and their "Others" was that White heterosexual men were at the top of the hierarchy. This left me with a single, horrible question: where could I find a place of pride for myself as a Black man with a disability? I don't like admitting to having had these views, and I don't believe in them anymore, but like all of us I was deeply affected by the world I grew up in and the values it imparted.

Well, now that we got that part-my current understanding of the theory-out of the way, I bet you are asking yourselves whether I have restricted myself to dating only other people with physical disabilities, just like how things were at boarding school? I would say that things have rather changed since then. Firstly, I can admit that after leaving school the dating pool has shrunk quite drastically, and predictably so. So, I had to spread my wings in other directions. Secondly, just like the famous singer I mentioned above, I have also become a bit of a sex symbol myself, just with less money and fame. With that, I am actually referring to a state of mind rather than a physical one. You might say that's rather arrogant and presumptuous of me, and I'd agree with you, except for the fact that as much as I had never seen myself as appealing, attractive and all that, 
the most unpredictable things have happened. I don't exactly know what to attribute this to, but being on the periphery or fringes of society has assisted me to understand and make sense of the world from a particular standpoint, and this has benefitted me romantically.

Now, I have no idea what it is like for non-disabled men experiencing confidence- and insecurity-related challenges as they grow up. In my case, though, I clearly remember my watershed moment. I want to refer to what a participant alluded to during a research project carried out by Gerschick and Miller (1995, p. 202). Eddie, one of the participants, made a comparison of himself, a man with a disability, with women's experiences. He said "...looking at himself in the mirror, in this context it is important to observe that people with disabilities often experience the unwanted attentions, intrusions, and stares with which women without disability are familiar". Eddie is a heterosexual, working-class man with spina bifida, who experiences a particular conflict in his way of navigating masculinity in the context of disability. Without getting into the intricate details of his utterances, the main idea from what he says is that he and men with disabilities in general "...do not automatically enjoy the power and privileges of men without disability and cannot be assumed to have access to the same physical resources" (1995, p. 202). Essentially, he suffers from a form of sexual oppression as a man with a disability and therefore sees himself first and foremost as a man a with disability rather than a heterosexual man. There is a rather complex issue of the hierarchy of identity politics here. He has something in common with women: a second class status in society's eyes, compared to heterosexual men.

I can completely relate to the above narrative by Eddie. Out of school and into mainstream society, I carried severe insecurities and deemed myself as inferior to my non-disabled peers. While I cannot deny that a majority of such perceptions and my self-image crisis were internal, many can also be attributed to the experience of the mainstream societal gaze, and the baggage that is attached to it. One is never really sure of the origin of such gazes, whether they are from a genuinely sincere and compassionate place, or simply from a person's need for satisfaction of their curiosity about the "other". Yet with all the baggage of the gaze, my watershed moment came at the end of a curious woman's gaze, albeit achieved at the cost of surprising honesty and vulnerability on her part. There was a coffee shop that I used to frequent during my lunch breaks. There was a woman who always used to take her break at the same time as me; there was nothing much to our relationship except the few and far 
between casual exchanges we'd make to each other. However, I remember one particular day when the coffee shop was full of patrons and all the tables were full, that I happened to be by myself at my table. She scanned the room for some open spaces, realised the only possible space would be at my table and headed straight to my table with her drink. I imagined she was going to wait for her meal to be delivered at my table. Now, you're probably thinking I saw this as my lucky day, but hell no, I got really anxious and started panicking. But at the back of my mind, I was thinking, "As soon as her food arrives, she'll leave me in peace to deal with my wimp-ish and meek tendencies". But she did nothing of the sort-she decided to have her meal at the table with me.

I honestly cannot remember the details of that conversation, but it lasted the entire duration of our lunch break. To cut the long story short, from that day we started to see more of each other and even took our conversations to other places besides the usual coffee shop. I would love to better describe how expressive and direct this woman was, but I think that would need its own chapter. Let me just say it was my first experience of an assertive, dominant and open-minded person, who definitely took note of my shy, inward disposition, but was still able to immerse herself into a world we both did not really understand. Somehow, she was able to extract and liberate the inner man concealed behind layers and layers of my so-called inferior masculinity in the context of disability. Now, retrospectively, I can admit that there was a whole degree of problematic objectification that took place in that experience. As such, I don't assume that-later in my life-I would have found the same relationship as fulfilling. However, for me, at that time of my life, given the number of confusing gazes and feedback I had been receiving up until that point, particularly from the opposite gender, this experience served a specific purpose. I grew to embrace the mirror reflections of myself a bit more, understood that societal projections are not always negative, but even when they are, one still can exercise one's own agency in how to deal with them. Lastly, I learnt that others, at times, will be able to see the positive in you, that which you are not able to admit to yourself because you are too caught up in the negative self-imposed perceptions. Most importantly, it normalised relationships for me: some will be good, some will be bad, some will just be normal, with both good and bad in them. But being a man with a physical disability doesn't make me feel more or less likely to have any of these experiences. It does not make me more or less of a partner, or more or less of a man. 


\section{REFERENCES}

Connell, R. W. (1995). Masculinities. Cambridge: Polity.

Gerschick, T. J., \& Miller, A. S. (1995). Coming to terms. In D. Sabo \& D. Gordon (Eds.), Men's health and illness (pp. 183-204). London: Sage.

Morris, J. (1991). Pride against prejudice. London: Women's Press.

Murphy, R. (1987). The body silent. London: Phoenix House.

Tiefer, L. (1995). Sex is not a natural act. Oxford: Westview Press.

Open Access This chapter is licensed under the terms of the Creative Commons Attribution 4.0 International License (http://creativecommons.org/licenses/ by $/ 4.0 /)$, which permits use, sharing, adaptation, distribution and reproduction in any medium or format, as long as you give appropriate credit to the original author(s) and the source, provide a link to the Creative Commons license and indicate if changes were made.

The images or other third party material in this chapter are included in the chapter's Creative Commons license, unless indicated otherwise in a credit line to the material. If material is not included in the chapter's Creative Commons license and your intended use is not permitted by statutory regulation or exceeds the permitted use, you will need to obtain permission directly from the copyright holder.

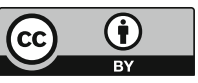

